\title{
Protein-mediated Adhesion of Lactobacillus fermentum Strain 737 to Mouse Stomach Squamous Epithelium
}

\author{
By PATRICIA L. CONWAY* AND STAFFAN KJELLEBERG \\ Department of Marine Microbiology, University of Göteborg, Carl Skottsbergs Gata 22, \\ S-413 19 Göteborg, Sweden
}

(Received 23 May 1988; revised 1 December 1988; accepted 4 January 1989)

The mechanism of adhesion of Lactobacillus fermentum strain 737 to mouse stomach squamous epithelium was investigated. Adhesion inhibition tests involving chelators, monosaccharides, periodate and concanavalin A and the use of bacteria grown in the presence of tunicamycin failed to clarify the adhesive mechanism. Washed bacterial cells had reduced adhesive capacity, except in the presence of spent broth culture supernatant fraction or cell washings. Spent culture supernatant fractions of erythrosine-supplemented broth did not enhance adhesion of washed cells. The adhesion-promoting factor(s) in the spent broth culture supernatant fractions and cell washings bound to both bacterial and epithelial cell surfaces, but did not promote adhesion of two other Lactobacillus strains which were not of mouse origin, thereby indicating host specificity for the adhesion-promoting activity. Chemical characteristics of the adhesionpromoting factor were determined by pretreatment of the dialysis retentate of spent broth culture supernatant fractions with proteolytic enzymes, concanavalin A-Sepharose or periodate before the adhesion assay. The adhesin was non-dialysable, pronase-sensitive, heat sensitive at $100^{\circ} \mathrm{C}$, had no affinity for concanavalin A-Sepharose and contained no carbohydrate groups active in the adhesion process. The protein profiles of dialysis retentates of spent broth culture supernatant fractions after bacterial growth in the absence and presence of erythrosine were determined by 2-dimensional SDS-PAGE. Gel filtration by HPLC was used for purification of an adhesion-promoting fraction. The host-specific adhesion of $L$. fermentum strain 737 was mediated by a protein, with an $M_{\mathrm{r}}$ of $12-13000$, that was not detectable in cells grown in the presence of erythrosine. A model for the mode of binding of the adhesin to host epithelia and bacterial surfaces is proposed.

\section{INTRODUCTION}

Host specificity in the colonization of the gastrointestinal tract by lactobacilli has been demonstrated both in vivo and in vitro for a range of hosts (Fuller, 1973; Suegara et al., 1975; Barrow et al., 1980; Tannock et al., 1982; Lin \& Savage, 1984).

Savage (1972) proposed that adhesion of indigenous Lactobacillus spp. to the keratinized squamous epithelium of the digestive tract of mice was mediated by the extracellular polysaccharide. This suggestion has been supported by other studies using chicken and pig stomach tissue and Lactobacillus strains of respective host origin (Brooker \& Fuller, 1975; Barrow et al., 1980). However, Wadström et al. (1987) showed that carbohydrate may not be involved in the adhesion of lactobacilli to the secreting epithelium of porcine ileum and suggested that different or multiple adhesion mechanisms may be involved. Using the rodent system, Suegara et al. (1975) showed no clear correlation between extracellular polysaccharide and adhesion, and proposed that hydrogen bonding may mediate adhesion via bacterial surface

Abbreviations: PB, phosphate buffer; BHI, Brain Heart Infusion; MRS broth, de Man, Rogosa and Sharpe Lactobacillus broth; LDM-II, Lactobacillus defined medium. 
components. Subsequently, Savage (1984) suggested that this adhesion may involve several extracellular components. Sherman \& Savage (1986) suggested a correlation between lipoteichoic acid and adhesion to rodent tissue. This team succeeded in transferring colonization capacity into non-colonizing strains by transformation of DNA from an adhesive strain (McCarthy et al., 1988). Conway \& Adams (1989) (preceding paper) demonstrated that addition of the red food colour erythrosine to the growth medium inhibited production of the bacterial component which mediated adhesion without affecting production of extracellular polysaccharide. The aim of the work presented here was to utilize the inhibition of expression of the adhesive factor(s) by erythrosine to study the mechanism of adhesion of Lactobacillus fermentum to squamous epithelium in the stomach of the mouse.

\section{METHODS}

Bacterial strains and culture conditions. L. fermentum 737 was isolated from mouse non-secreting stomach tissue (Conway \& Adams, 1989). L. fermentum strain 737A was selected following the transfer of strain 737 at least 30 times in MRS broth (Oxoid) which induced a loss in adhesive capacity. L. fermentum strain 6991 was a gift from Professor A. Wicken, School of Microbiology, University of New South Wales, Australia, and was originally isolated from the human oral cavity. Lactobacillus acidophilus strain ADH, which was isolated from a human, was a gift from Dr T. R. Klaenhammer, Department of Food Science, North Carolina State University, USA. It adhered well to human and pig ileal cells (Conway et al., 1987). Strains were maintained at $-20{ }^{\circ} \mathrm{C}$ in $15 \%$ (v/v) glycerol with reserve stocks in a freeze-dried state.

All cultures were incubated anaerobically at $37^{\circ} \mathrm{C}$ and inocula were prepared as previously described (Conway \& Adams, 1989). Cultures were grown in Brain Heart Infusion broth or on agar (BHI; Oxoid), Lactobacillus MRS broth (MRS; Oxoid), the defined medium LDM-II (according to Kotarski \& Savage, 1979, except that Tween 80 was not included) and an MRS diffusate broth. The MRS diffusate broth (A. Wicken, personal communication) was prepared in order to produce a medium in which all constituents would pass through a dialysis membrane with a $M_{\mathrm{r}}$ 6000-8000 cut-off (Spectrum Medical Industries). This was achieved by collecting the diffusate from a dialysis sack containing a concentrated solution of MRS broth ( $55 \mathrm{~g}$ powder per $100 \mathrm{ml}$ water) and then diluting the diffusate to 1 litre with Milli-Q water (Millipore; double-distilled, deionized, passed through a carbon filter). This MRS diffusate broth and the BHI broth were supplemented with $2 \%(\mathrm{w} / \mathrm{v})$ glucose and filter-sterilized $(0 \cdot 20 \mu \mathrm{m} ;$ Nuclepore). Erythrosine (2,4,5,7-tetraiodofluorescein, disodium salt) was a food-grade preparation (Edicol erythrosine; ICI Australia) and was included in the growth media, when specified, at concentrations of 0.05 and $0.1 \%(\mathrm{w} / \mathrm{v})$. For adhesion studies using radioactively labelled bacteria, $\left[\right.$ methyl, $\left.1^{\prime}, 2^{\prime}-{ }^{3} \mathrm{H}\right]$ thymidine (Amersham), specific activity $117 \mathrm{Ci} \mathrm{mmol}^{-1}\left(4.33 \mathrm{TBq} \mathrm{mmol}^{-1}\right)$ was added to the various media to give a final concentration of $10 \mu \mathrm{Ci} \mathrm{ml}^{-1}\left(37 \mathrm{MBq} \mathrm{m}^{-1}\right)$.

In vitro adhesion assay. Gastric epithelia were collected from BalbC mice as previously described (Conway \& Adams, 1989). The bacteria were harvested from growth media and washed in PBS according to Conway \& Adams (1989). The final bacterial pellet was resuspended in $1 \mathrm{ml}$ PBS prior to dilution, as detailed below, to give an $\mathrm{OD}_{600}$ of 1.0 . The bacterial suspensions in the various diluents were allowed to equilibrate at $5{ }^{\circ} \mathrm{C}$ for $15 \mathrm{~min}$ before being used in the adhesion assay. For studies using radioactively labelled bacteria, the number of bacteria per $\mathrm{ml}$ was determined using a microcomputerized Elzone ADC 80XY particle counter with a $12 \mu \mathrm{m}$ orifice tube and a chart recorder. PBS was used as both the diluent and the internal fluid.

The adhesion assay was done by incubating the tissue pieces in the bacterial suspensions. The tissue pieces were subsequently washed according to Conway \& Adams (1989). The degree of adhesion was monitored by either scanning electron microscopy (Adams \& Conway, 1981) or by determination of the number of radioactively labelled bacteria per mg wet wt of tissue. For the latter method, washed tissue pieces were individually weighed and then digested in glass scintillation vials using perchloric acid and hydrogen peroxide (Kotarski \& Savage, 1979). Aquassure (Amersham) scintillation fluid $(5 \cdot 5 \mathrm{ml})$ was added to the digested tissue and to bacterial control solutions. The radioactivity of each sample was measured using a Packard liquid scintillation counter. For comparison of various treatments, an adhesion index was calculated as the percentage of the ratio of the number of bacteria adhering per mg of tissue to the maximum number of adhering bacteria within the study or the number of bacteria adhering in the control (Fuller, 1975).

Leakage of the radioactive label from the bacterial cells and uptake of that label by the tissue was measured by sampling the PBS diluent of the bacterial suspension at the beginning and end of the 30 min incubation time and by incubating additional tissue pieces with this material. The radioactivity of the PBS diluent supernatants and the tissue pieces was determined, as well as the loss of the label from the cells and the uptake by the tissue.

Test for inhibition of adhesion to mouse stomach epithelium. L. fermentum strain 737 was grown in BHI broth containing $2 \%(\mathrm{w} / \mathrm{v})$ glucose and $\left[{ }^{3} \mathrm{H}\right]$ thymidine $\left(10 \mu \mathrm{Ci} \mathrm{m}^{-1}\right)$. The potential inhibitors were added to the diluent 
used in the in vitro adhesion assay. The compounds were added separately to yield final concentrations of $0 \cdot 11 \mathrm{M}$ mannose, $0.12 \mathrm{M}$-D-fucose, $3.6 \mathrm{mM}-\mathrm{CaCl}_{2}, 2.5 \mathrm{~mm}-\mathrm{Na}_{2}$ EDTA, $2.5 \mathrm{~mm}$-EGTA, $0.2 \mathrm{mg}$ concanavalin A (Sigma) per $\mathrm{ml}$ of assay mixture and $47 \mathrm{~mm}$-sodium metaperiodate. The effect of tunicamycin $\left(1 \mu \mathrm{g} \mathrm{ml}^{-1}\right)$ was tested by addition to the growth medium.

Addition of untreated and treated culture supernatant fractions to the adhesion assay. Washed cell suspensions of $L$. fermentum strain 737A, which were not radioactively labelled, were diluted with either uninoculated BHI broth or spent BHI broth culture supernatant fraction after growth of L. fermentum strains 737 and $737 \mathrm{~A}$ and removal of the cells by centrifugation. In addition, the strain 737 culture supernatant fraction and uninoculated BHI broth were dialysed against Milli-Q water using dialysis tubing with an $M_{\mathrm{r}} 6000-8000$ cut-off. The BHI broth and spent BHI broth culture supernatant fractions, before and after heating at $100^{\circ} \mathrm{C}$, were also used as diluents in the adhesion assay. To ascertain the specificity of any substances in the culture supernatant fraction, washed bacterial suspensions of $L$. acidophilus strain $\mathrm{ADH}$ and of $L$. fermentum strain 6991 grown in BHI broth were similarly pretreated with BHI broth culture supernatant fraction from L. fermentum strain 737 and tested for adhesion capacity. The adhesion was monitored by scanning electron microscopy.

Cell suspensions of BHI-broth-grown and ${ }^{3} \mathrm{H}$-labelled cells were washed in PBS and the second wash solution was collected and used as a diluent for the cells. The dialysis retentates of culture supernatant fractions of strain 737 after growth in either MRS broth, LDM-II defined medium, BHI broth, or BHI broth containing $0.1 \%$ erythrosine were also used as diluents. Tissue pieces were also pretreated with either uninoculated medium or strain 737 culture supernatant fraction prior to the adhesion assay. In addition, washed $L$. fermentum cells grown in LDM-II defined medium were pretreated with $0-200 \mu \mathrm{l}$ of the dialysis retentate of spent culture supernatant fraction of LDM-II defined medium per $\mathrm{ml}$ PBS and then tested for adhesion. The numbers of adhering bacteria were enumerated by measuring the radioactive label.

To characterize the adhesion-promoting material in the culture supernatant fractions, the dialysis retentates of uninoculated media and of corresponding spent culture supernatant fractions of BHI, LDM-II and MRS diffusate broths after growth of $L$. fermentum strain 737 , were pretreated with various compounds prior to being used as diluents in the in vitro adhesion assay. L. fermentum strain 737 cells, grown in $\mathrm{BHI}$ broth containing $\left[{ }^{3} \mathrm{H}\right]$ thymidine were washed in PBS and tested for adhesive capacity in the presence of treated dialysis retentates of broth and spent culture supernatant fractions. The dialysis retentates were prepared using Milli-Q water and had a final $\mathrm{pH}$ in the range $6 \cdot 8-7 \cdot 0$.

A mini-column containing $2 \mathrm{ml}$ concanavalin A-Sepharose (Pharmacia) was prepared and washed with

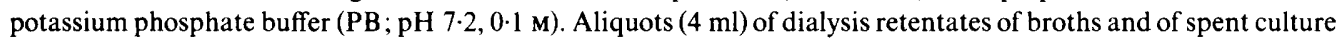
supernatant fractions were individually passed through the column and the eluates collected. Remaining unbound material was eluted from the column with PB and these washings were then pooled with the respective eluates. Sodium metaperiodate $(47 \mathrm{~mm})$ was added to dialysis retentates of broth and spent culture supernatant fractions; after $30 \mathrm{~min}$ at $20^{\circ} \mathrm{C}$, ethylene glycol $(2 \%, \mathrm{v} / \mathrm{v})$ was added to stop the reaction. The mixture was then dialysed against Milli-Q water to remove excess periodate. As a control, ethylene glycol was also included in non-periodatetreated samples. Pronase ( $2 \mathrm{mg} \mathrm{ml}^{-1}$; Calbiochem) and trypsin $\left(2 \mathrm{mg} \mathrm{ml}^{-1}\right.$; Sigma) were added individually to dialysis retentates and spent culture supernatant fractions and the mixtures were incubated at $37^{\circ} \mathrm{C}$ for $1 \mathrm{~h}$. When these solutions were used as diluents for the bacterial suspensions in the adhesion assay, all procedures were done on ice. EGTA $(1.5 \mathrm{~mm})$ was similarly added to dialysis retentates of broth and of spent culture supernatant fractions from LDM-II defined medium prior to the adhesion assay. Tunicamycin $\left(1 \mu \mathrm{g} \mathrm{ml} \mathrm{m}^{-1}\right)$ was added to MRS diffusate broth before growth of $L$. fermentum strain 737 and then the dialysis retentate of the spent culture supernatant fraction was tested for the presence of the adhesion-promoting activity.

Purification of the adhesion-promoting material. All concentration procedures were done on dialysis retentates of both broth LDM-II and MRS diffusate and of their corresponding spent culture supernatant fractions after growth of $L$. fermentum strain 737 . Samples were stored at $-20^{\circ} \mathrm{C}$ and aliquots were thawed immediately prior to testing. Samples were concentrated by both freeze-drying and precipitation with acetone. For the latter process, the samples were held in an ice-bath adjusted to $-21^{\circ} \mathrm{C}$ (by adding $33 \mathrm{~g} \mathrm{NaCl}$ to $100 \mathrm{~g}$ ice) and an equal volume of prechilled acetone was added while stirring. After an additional $10 \mathrm{~min}$ of continuous stirring, the mixture was centrifuged at $10000 \mathrm{~g}$. The pellet was collected and stored over silica gel until dry.

The protein profiles of the filtered $(0.2 \mu \mathrm{m}$; Nuclepore), dried concentrates of dialysis retentates of LDM-II broth and of spent LDM-II culture supernatant fraction were analysed by 2-dimensional SDS-PAGE with the first dimension being isoelectric focusing and visualized by silver staining according to Jouper-Jaan et al. (1987). The concentrates were diluted in Milli-Q water to yield protein concentrations of $0 \cdot 2-0 \cdot 3 \mathrm{mg} \mathrm{ml}^{-1}$ (measured according to Whitaker \& Garnum, 1980), diluted with an equal volume of lysis buffer which contained $9 \cdot 5 \mathrm{M}$-urea, $2 \%$ (w/v) Nonidet P-40, 5\% (w/v) 2-mercaptoethanol, 1.6\% (w/v) Ampholine pH range 5-7 (LKB), 0.4\% Ampholine $\mathrm{pH}$ range 3.5-10. A $40 \mu \mathrm{l}$ sample of this mixture was added per gel.

The same samples were also subjected to affinity chromatography on a bed of concanavalin A-Sepharose and the non-retained material examined by 2-dimensional SDS-PAGE as above. The dialysis retentate of spent culture 
supernatant fraction from growth of $L$. fermentum strain 737 in LDM-II broth containing $0 \cdot 1 \%$ erythrosine was also analysed by 2 -dimensional SDS-PAGE. Additional gels were stained using the Schiff-periodic acid reaction (Sigma kit) to detect carbohydrate groups on glycoproteins.

Dialysis retentates of both broth and spent culture supernatant fractions were fractionated using an LKB HPLC system with an LKB 21250 pump, an LKB 2152 controller and an LKB 2151 wavelength monitor. The pre-column was an UltraPac-TSK-GSWP $(7.5 \times 75 \mathrm{~mm})$ and the main column an UltraPac TSK-G3000 SW, TP 5000, gel filtration column $(7.5 \times 3000 \mathrm{~mm})$ with an $M_{\mathrm{r}}$ range of 1000-300000. An anionic column, UltraPac TSK DEAE-5 PW $(7.5 \times 75 \mathrm{~mm})$, was also used. The buffer was $10 \mathrm{~mm}-\mathrm{Tris} / \mathrm{HCl}, \mathrm{pH} 7.5$, containing $1 \mathrm{M}$-glycerol and $0.05 \%$ sodium azide and the flow rate through the gel filtration column was $0.5 \mathrm{ml} \mathrm{min}^{-1}$. For the anionic column, the gradient programme was as follows: $0-10 \mathrm{ml}$, Tris buffer as above; $10-20 \mathrm{ml}, 0-0.5 \mathrm{M}-\mathrm{NaCl} ; 20-22 \mathrm{ml} ; 0.5-$ $1.37 \mathrm{M}-\mathrm{NaCl} ; 22-26 \mathrm{ml}$, rinse with $1.37 \mathrm{M}-\mathrm{NaCl} ; 26-35 \mathrm{ml}$, Tris buffer.

Fractions corresponding to the individual protein peaks were collected manually according to the individual peaks and the collection points annotated on the chromatogram. The pooled fractions were assayed for adhesionpromoting activity using washed, radioactively labelled cells of $L$. fermentum strain 737 that had been grown in BHI broth. The $M_{\mathrm{r}}$ of the adhesion-promoting material was estimated using the $M_{\mathrm{r}}$ standards kit for both highand low- $M_{\mathrm{r}}$ compounds (Pharmacia). The standards and purified adhesion-promoting factor (stored at $-20^{\circ} \mathrm{C}$ ) were fractionated using the HPLC system as for the dialysis retentates of broth and spent culture supernatant fraction. The $M_{\mathrm{r}}$ values were estimated from a plot of $\log M_{\mathrm{r}}$ against $K_{\mathrm{av}}$.

\section{RESULTS}

\section{Inhibition of adhesion to mouse stomach epithelium}

Varying degrees of inhibition of Lactobacillus adhesion to mouse stomach squamous epithelium were observed when mannose, D-fucose, EDTA, concanavalin A and periodate were included just before the assay. EGTA had little effect, but $\mathrm{CaCl}_{2}$ promoted binding (Table 1). Cells grown in the presence of tunicamycin were unchanged in their adhesion capacity (data not shown).

\section{Adhesion-promoting activity of the culture supernatant fractions}

PBS-washed cells of BHI-agar-grown, but not of BHI-broth-grown L. fermentum strain 737A bound to stomach epithelial pieces. Adhesion was restored, however, when washed BHI-brothgrowth cells were pretreated with culture supernatant fractions from the growth of L. fermentum strains 737 and 737 A in BHI broth (Table 2). Dialysed, but not heat-treated, culture supernatant fractions also restored binding. This promotion of adhesion in the presence of culture supernatant fraction did not occur with the other Lactobacillus strains tested.

The adhesion of washed BHI-broth-grown L. fermentum strain 737 was enhanced by about $50 \%$ when bacteria were pretreated with dialysis retentates of spent culture supernatant fractions from the growth of this strain in BHI, MRS diffusate and LDM-II broths, or with the PBS in which the bacteria were washed (Table 3). In addition, pretreatment of the tissue surface with the dialysis retentate of spent BHI culture supernatant fractions also enhanced adhesion. This effect was not seen when the bacteria were also pretreated with BHI dialysis retentate. However, the dialysis retentate of spent culture supernatant fractions from growth of strain 737 in BHI broth containing erythrosine did not enhance binding. When washed cells of $L$. fermentum strain 737, grown in LDM-II broth, were pretreated with buffer containing 0-200 $\mu$ l of dialysis retentate of LDM-II spent culture supernatant fraction per ml of buffer, enhancement of adhesion was directly proportional to the amount of dialysis retentate used with both $1 \times 10^{3}$ and $1.4 \times 10^{4}$ bacteria per $\mathrm{mg}$ wet wt of tissue.

From the control experiments using bacterial cells labelled with $\left[{ }^{3} \mathrm{H}\right]$ thymidine, it was shown that the mean loss of label from the bacterial cells when resuspended in PBS was $4.9 \pm 2.2 \%$ and over the $30 \mathrm{~min}$ incubation period this increased by $1 \cdot 1 \pm 0.5 \%$. This confirmed that leakage of label from the cells during the course of the experiment was low and would not influence estimation of the number of adhering bacteria by measuring the radioactivity bound to the epithelial tissue. 
Table 1. Effects of test compounds on the adhesion of L. fermentum strain 737, grown in BHI broth containing $2 \%(w / v)$ glucose, to mouse stomach squamous epithelium

Adhesion index $=$ number of bacteria adhering per $\mathrm{mg}$ of epithelium expressed as a percentage of the number adhering per $\mathrm{mg}$ of epithelium in the control run in parallel. Bacterial numbers were enumerated by measuring the radioactivity of ${ }^{3} \mathrm{H}$-labelled bacteria. The mean number $\pm \mathrm{SD}$ adhering to control epithelium was $9.2 \pm 1.7 \times 10^{4}$ per $\mathrm{mg}$ wet wt of tissue. Results represent the mean value $\pm \mathrm{SD}$ of $n$ individual experiments each involving three assays, where $n$ is in parentheses. Where the given mean is for one individual experiment, the results are typical of three experiments. The adhesion index was calculated for each individual experiment.

Test compound

Mannose $(0 \cdot 11 \mathrm{M})$

D-Fucose $(0 \cdot 12 \mathrm{M})$

$\mathrm{CaCl}_{2}(3.6 \mathrm{mM})$

EDTA $(2.5 \mathrm{~mm})$

EGTA $(2.5 \mathrm{~mm})$

Concanavalin A $(0.2 \%, \mathrm{w} / \mathrm{v})$

Sodium metaperiodate $(47 \mathrm{~mm})$
Adhesion index

(\%)

$$
\begin{array}{r}
86 \pm 7(1) \\
75 \pm 6(1) \\
154 \pm 11(1) \\
63 \pm 5(1) \\
92 \pm 9(1) \\
46 \pm 13(3) \\
72 \pm 0 \cdot 8(4)
\end{array}
$$

\begin{tabular}{|c|c|c|c|c|}
\hline \multirow[b]{2}{*}{ Species/strain } & \multirow[b]{2}{*}{$\begin{array}{l}\text { Growth } \\
\text { medium }\end{array}$} & \multirow[b]{2}{*}{$\begin{array}{c}\text { Source of BHI } \\
\text { culture supernatant } \\
\text { fractions added to } \\
\text { assay }\end{array}$} & \multicolumn{2}{|c|}{$\begin{array}{l}\text { Adhesion of lactobacilli } \\
\text { after pretreatment with:* }\end{array}$} \\
\hline & & & BHI broth & $\begin{array}{c}\text { BHI culture } \\
\text { supernatant } \\
\text { fraction }\end{array}$ \\
\hline L. fermentum 737A & A & Strain 737 & $10 \cdot 2 \pm 1 \cdot 8$ & $9 \cdot 5 \pm 2 \cdot 1$ \\
\hline L. fermentum 737A & B & Strain 737 & 0 & $9 \cdot 2 \pm 1.6$ \\
\hline L. fermentum 737A & B & $\begin{array}{l}\text { Strain } 737 \mathrm{~A}, \\
\text { dialysis retentate } \dagger\end{array}$ & 0 & $14 \cdot 1 \pm 2 \cdot 2$ \\
\hline L. fermentum $737 \mathrm{~A}$ & B & $\begin{array}{l}\text { Strain } 737 \text {, } \\
\text { dialysis retentate } \uparrow\end{array}$ & 0 & $11 \cdot 0 \pm 1 \cdot 5$ \\
\hline L. fermentum 737A & B & $\begin{array}{l}\text { Strain } 737 \text {, } \\
\text { heated } 100^{\circ} \mathrm{C} \ddagger\end{array}$ & 0 & 0 \\
\hline L. fermentum 6991 & B & Strain 737 & 0 & 0 \\
\hline L. acidophilus ADH & B & Strain 737 & 0 & 0 \\
\hline
\end{tabular}

Table 2. Effects of the culture supernatant fractions of L. fermentum strains 737 and $737 \mathrm{~A}$ grown in BHI broth on adhesion of Lacobacillus strains to mouse squamous epithelium

The lactobacilli used in the adhesion assay were grown on either BHI agar (A) or BHI broth (B).

* Adhesion was monitored by SEM and results are presented as the number of bacteria adhering per $100 \mu \mathrm{m}^{2}$ of epithelium. Results are typical of three individual experiments and values represent the mean values \pm SD, calculated from counts of 27 separate fields of $960 \mu \mathrm{m}^{2}$. Where $75 \%$ or greater of the fields contained no bacteria and the remainder contained less than 10 , results are expressed as zero.

$\dagger$ Dialysis of BHI broth and spent culture supernatant fraction against Milli-Q water using dialysis tubing with an $M_{\mathrm{r}}$ cut-off of $6000-8000$.

$\ddagger$ Both BHI and spent culture supernatant fraction were heat-treated.

\section{Characteristics of the adhesion-promoting factor(s) in dialysis retentates of spent culture supernatant fractions}

The passage of dialysis retentates of broth or of the spent BHI culture supernatant fraction through the concanavalin A-Sepharose gel bed did not alter the adhesion-promoting activity of 
Table 3. Effect of pretreatment of either bacterial cells or epithelial pieces with dialysis retentates of spent culture supernatant fractions of various media on the adhesion of L. fermentum strain 737 to mouse squamous epithelium in an in vitro adhesion assay

Adhesion was monitored by measuring radioactivity due to $\left[{ }^{3} \mathrm{H}\right]$ thymidine associated with bound cells.

\begin{tabular}{|c|c|c|c|c|}
\hline $\begin{array}{l}\text { Pretreatment } \\
\text { fluid* }\end{array}$ & $\begin{array}{c}\text { Bacterial } \\
\text { pretreatment }\end{array}$ & $\begin{array}{c}\text { Tissue } \\
\text { pretreatment }\end{array}$ & $\begin{array}{c}\text { Washing } \\
\text { step post } \\
\text { pretreatment } \dagger\end{array}$ & $\begin{array}{l}\text { Adhesion } \\
\text { index }\end{array}$ \\
\hline MRS & - & - & - & $50 \pm 0(2) \S$ \\
\hline MRS & + & - & - & $100 \pm 0(2)$ \\
\hline MRS & - & + & - & $99 \pm 0(2)$ \\
\hline MRS & - & + & + & $32 \pm 1(1) \S$ \\
\hline MRS & + & + & - & $54 \pm 1(1) \S$ \\
\hline BHI & - & - & - & $53 \pm 6(4) \S$ \\
\hline BHI & + & - & - & $94 \pm 8(4)$ \\
\hline BHI + erythrosine & + & - & - & $43 \pm 9(4) \S$ \\
\hline LDM-II & - & - & - & $50 \pm 7(3) \S$ \\
\hline LDM-II & + & - & - & $97 \pm 5(3)$ \\
\hline PBS & - & - & - & $46 \pm 2(1) \S$ \\
\hline PBS cell washings & + & - & - & $100 \pm 0(1)$ \\
\hline
\end{tabular}

* Dialysis retentates of spent culture supernatant fractions of L. fermentum strain 737 after growth in MRS, BHI, BHI + erythrosine $(0 \cdot 1 \%$ w/v) or LDM-II broth. In addition, L. fermentum strain 737 BHI-broth-grown cells $\left(10^{9}\right)$ were washed using a Vortex mixer and I ml PBS. The resultant supernatant fraction was used as one of the pretreatment fluids and the results compared to those obtained when PBS was used alone.

$\dagger$ After pretreatment, the dialysis retentate of the spent culture supernatant fraction was either allowed to remain in the in vitro assay or was washed away with PBS as indicated.

$\ddagger$ Adhesion index $=$ (number of adhering bacteria per $\mathrm{mg}$ wet wt of tissue/maximum number of adhering bacteria per assay) $\times 100$ according to Fuller (1975) and expressed as the mean \pm SD. Numbers in parentheses represent the numbers of individual experiments, each involving three assays. The maximum number of adhering bacteria used as the denominator to calculate the adhesion index was restricted to samples using the same pretreatment fluid, except for BHI + erythrosine which is presented as a percentage of the BHI value, and the PBS/PBS cell washings which are compared. The mean numbers of bacteria \pm SD adhering to control epithelium were $1.43 \pm 0 \cdot 22,1 \cdot 2 \pm 0 \cdot 18,2 \cdot 47 \pm 0.32$ and $0.92 \pm 0 \cdot 2$, all $\times 10^{4}$ for BHI, MRS, LDM-II and PBS buffer, respectively.

$\S$ Significantly different from the maximum value $(P<0 \cdot 01)$ using Student's $t$-test.

either (Table 4). Similarly, pretreatment of the spent broth dialysis retentates with periodate (Table 4) or EGTA (data not shown) had no effect on the adhesion-promoting activity. The adhesion-promoting activity was destroyed by the action of pronase (Table 4) and partially inactivated by trypsin ( $38.8 \%$ of that obtained for pronase). The activity remained unchanged in the dialysis retentate of spent MRS diffusate broth culture supernatant fraction after growth of strain 737 in the presence of tunicamycin (data not shown). Preliminary experiments using pronase-treated dialysis retentate of MRS diffusate broth culture supernatant fraction were done at room temperature. Under these experimental conditions the pronase remained active and the tissue epithelium was partially damaged during the course of the adhesion assay. However, when the adhesion assay mixture was incubated on ice, the control values for the adhesion index remained about $50 \%$ (Table 4 ) in the absence or presence of pronase.

The 2-dimensional gel electrophoresis of dialysis retentate of LDM-II broth showed that it was free of polypeptides (Fig. $1 a$ ), whereas that of the spent culture supernatant fraction of $L$. fermentum strain 737 contained several proteins (Fig. $1 b$ ), all of which appeared to be eluted from the concanavalin A-Sepharose column (Fig. 1 c). The additional low $M_{\mathrm{r}}$ spots (marked with an arrowhead in Fig. 1c) were consistent with the material eluted from the concanavalin A-Sepharose column by the buffer alone (data not shown). Only two of the proteins in the dialysis retentate of spent LDM-II culture supernatant fraction (marked with 
Table 4. Effects of treatments with various reagents on the adhesion-promoting activity of the dialysis retentate of spent BHI culture supernatant fractions, from growth of L. fermentum strain 737, on adhesion of strain 737 cells to mouse epithelium

Adhesion was monitored by measuring radioactivity associated with $\left[{ }^{3} \mathrm{H}\right]$ thymidine-labelled cells of strain 737 . After dialysis, retentates were pretreated with the reagents as described in the footnote, and then used as the diluent for the bacterial cells used in the adhesion assay.

\begin{tabular}{|c|c|c|}
\hline \multirow{2}{*}{$\begin{array}{l}\text { Reagents used in } \\
\text { pretreatment of BHI } \\
\text { dialysis retentate }\end{array}$} & \multicolumn{2}{|c|}{$\begin{array}{c}\text { Adhesion index }(\%) \text { in the } \\
\text { presence of } \mathrm{BHI} \text { dialysis } \\
\text { retentate* }\end{array}$} \\
\hline & Broth & Spent culture \\
\hline Control & $53 \pm 6(4)$ & $94 \pm 8(4)$ \\
\hline Concanavalin A-Sepharose $\dagger$ & $49 \pm 2(2)$ & $94 \pm 7(4)$ \\
\hline Periodate $\ddagger$ & $45 \pm 6(3)$ & $93 \pm 6(3)$ \\
\hline Ethylene glycol§ & $51 \pm 4(3)$ & $95 \pm 5(3)$ \\
\hline Pronase $\|$ & $47 \pm 7(3)$ & $54 \pm 6(3)^{* *}$ \\
\hline
\end{tabular}

* Adhesion index, as described in Table 3, represents the percentage of cells adhering to the epithelium relative to control values. The number of individual experiments, each involving three assays are included in parentheses. The untreated (control) spent BHI culture diffusate value of $94 \pm 8$ (4) corresponded to $1.43 \pm 0.22 \times 10^{4}$ bacterial cells per $\mathrm{mg}$ wet wt of epithelium. Results are presented for BHI broth and dialysis retentate of spent culture supernatant fraction and are typical of those obtained using LDM-II and MRS diffusate broths in three or four individual experiments. ${ }^{* *} P<0.01$ in Student's $t$-test.

$\uparrow$ The dialysis retentate of culture supernatant fraction was passed through a concanavalin A-Sepharose column and the eluate collected and tested.

$\ddagger$ Sodium metaperiodate was added to the dialysis retentate and after $30 \mathrm{~min}$ at $20^{\circ} \mathrm{C}$, ethylene glycol $(2 \%, \mathrm{v} / \mathrm{v})$ was added to stop the reaction. The mixture was then dialysed to remove excess periodate.

$\S$ Ethylene glycol $(2 \%, \mathrm{v} / \mathrm{v})$ was added to the dialysis retentate as a control for the periodate test.

$\|$ Pronase $\left(2 \mathrm{mg} \mathrm{ml}^{-1}\right)$ was added to the diffusates and the mixture incubated for $1 \mathrm{~h}$ at $37^{\circ} \mathrm{C}$. The bacterial suspensions in these diffusates were kept on ice and the adhesion assay done on ice to prevent further action of the pronase. Controls were also kept on ice.

circles) were detected in the dialysis retentate of spent LDM-II culture supernatant fractions containing $0.1 \%$ erythrosine (Fig. $1 d$ ). No carbohydrate-containing proteins were detected using the Schiff-periodic acid stain. This may be due to the insensitivity of the stain for the small quantity of sample on the gel.

\section{HPLC fractionation of concentrates of dialysis retentates of spent culture supernatant fractions}

Fractionation of the dialysis retentate of spent culture supernatant fractions of LDM-II and MRS diffusate broth that had been stored at $-20^{\circ} \mathrm{C}$ or concentrated by freeze-drying consistently yielded an adhesion-promoting fraction with the same retention time on the gel filtration column in the HPLC system (Fig. $2 a$ ). A similar peak was detected in the bacterial cell washings (data not shown). The fraction which contained the adhesion-promoting activity was then passed through the HPLC gel filtration column again to remove contaminating material as one passage through such a gel filtration column was inadequate to yield a pure fraction. This second passage yielded a high- $M_{\mathrm{r}}(>90000)$ component which contained some activity and three others with retention times very similar to the active fraction (Fig. $2 a$ ), thus confirming that the active peak in Fig. 2(a) was not pure. These later peaks generated from the second passage were tested for activity and pooled positive fractions from several runs were again passed through the gel filtration column to determine purity (Fig. 2b). After the second passage through the column, a single peak was obtained with an $M_{\mathrm{r}}$ of about $12-13000$. This material showed no interaction with an HPLC anionic column as it was eluted before the commencement of the $\mathrm{NaCl}$ gradient. 


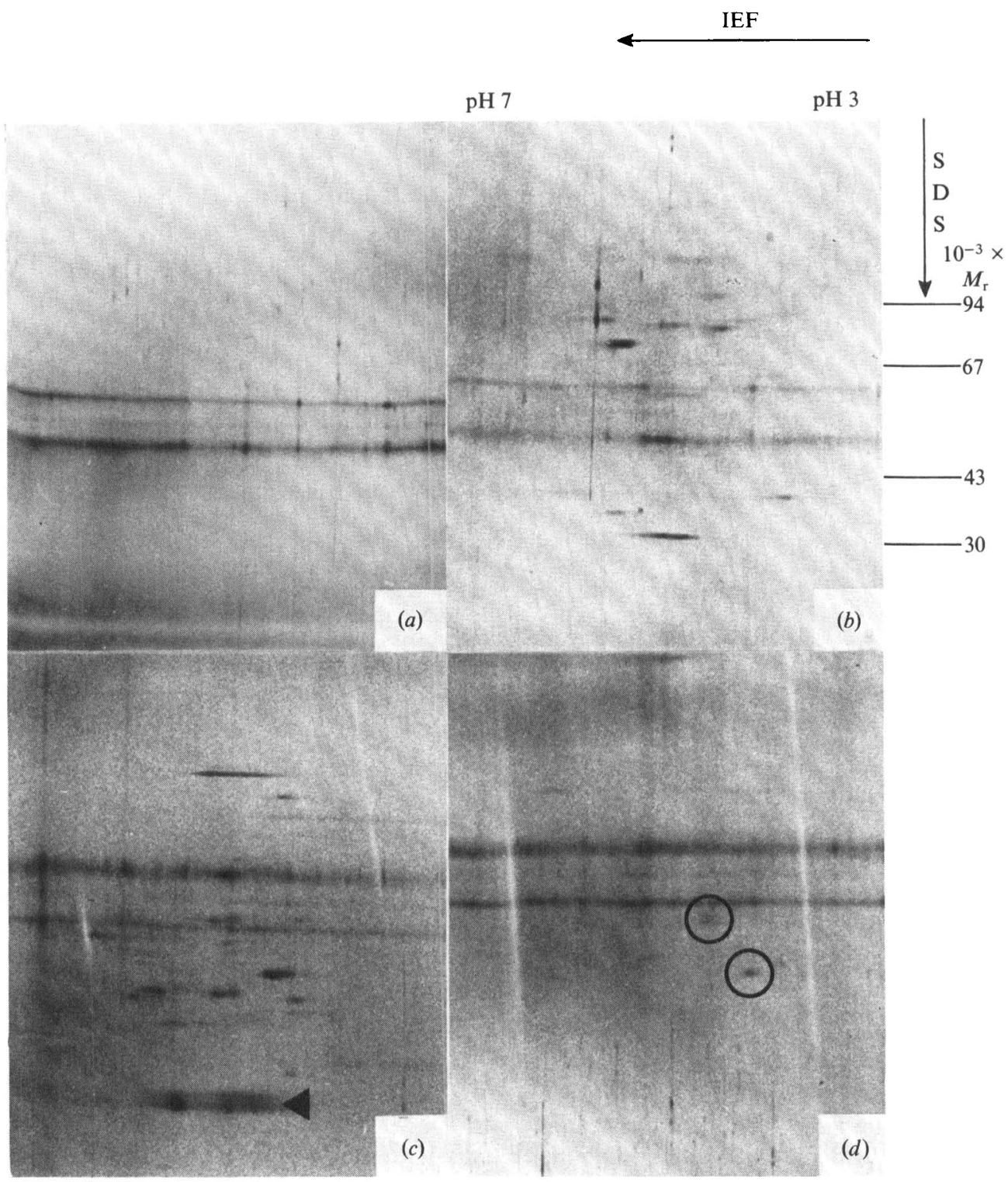

Fig. 1. Two-dimensional electrophoresis gels of metabolites of L. fermentum strain 737. (a) Uninoculated LDM-II broth; (b) LDM-II spent culture dialysis retentate; (c) LDM-II spent culture dialysis retentate after passage through a concanavalin A-Sepharose gel bed; $(d)$ LDM-II $+0 \cdot 1 \%$ erythrosine spent culture dialysis retentate. The isoelectric focusing first dimension is presented as the horizontal axis and the $M_{\mathrm{r}}$-SDS dimension on the vertical axis. The positions of $M_{\mathrm{r}}$ standards (run on a separate gel) are indicated. 


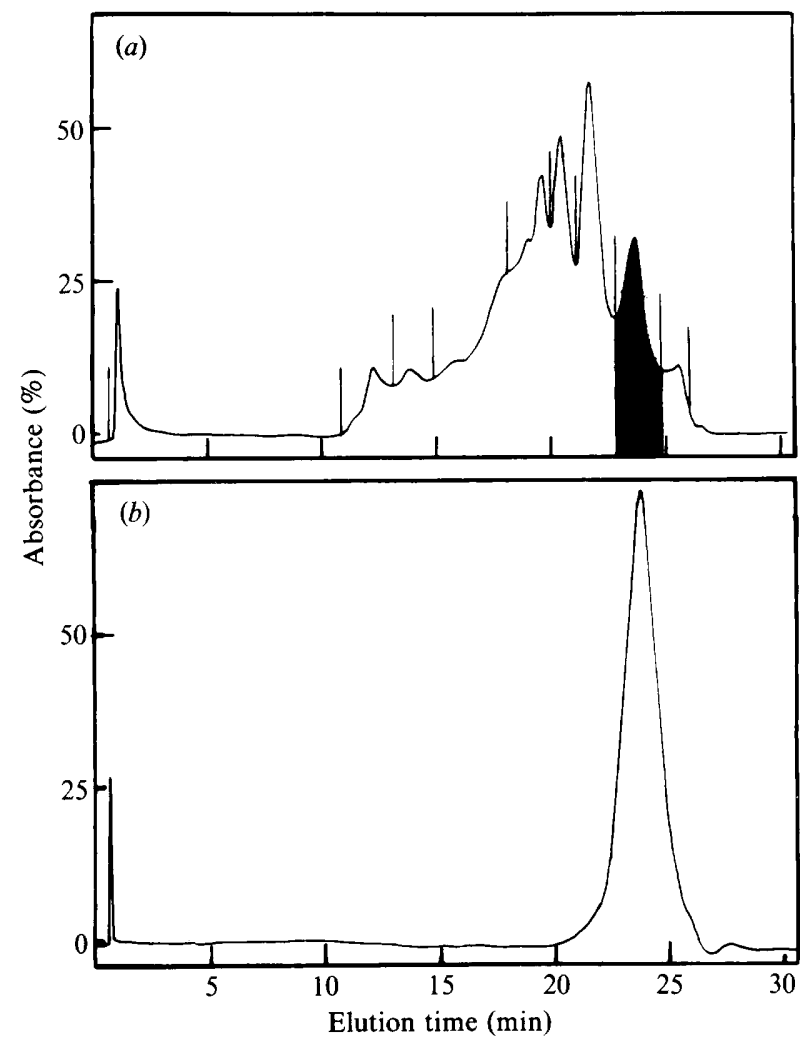

Fig. 2. HPLC of dialysis retentate of $L$. fermentum broth culture containing adhesion-promoting activity. Chromatograms of UV-absorbance plotted against time of elution of the elution of UVabsorbing material from the gel-filtration column using the HPLC system and Tris buffer for separating the adhesive determinants from $L$. fermentum strain 737 spent culture dialysis retentate. (a) MRS broth spent culture dialysis retentate. Activity was localized in the shaded fraction. Vertical lines on the chromatogram trace indicate times of collection of individual fractions. The void volume corresponded to $8 \mathrm{~min}$. (b) Purified active fraction from pooled active fractions in $(a)$.

\section{DISCUSSION}

The addition of various potential inhibitors to either the growth medium, the adhesion assay diluent or to the diluent prior to the assay failed to clarify the mechanism of adhesion as no definite trend was detectable. Although mannose and $\mathrm{D}$-fucose have been implicated in inhibiting some adhesion systems, the limited inhibition herein suggests that these compounds do not function as the receptors. The reduction of adhesion by EDTA implies that there is some divalent cation bridging which probably does not involve calcium because EGTA, which is specific for calcium (Turakhia et al., 1983), did not reduce binding. Suegara et al. (1975) showed no effects of EDTA on adhesion of $L$. fermentum to rat tissue and Fuller (1975) found no effect of EDTA on adhesion of L. acidophilus to chicken tissue. Cation-enhanced adhesion of lactobacilli to cell monolayers has been demonstrated to be distinct from adhesion in the absence of the cations (Kleeman \& Klaenhammer, 1982) and is consistent with the enhanced adhesion in the presence of calcium herein (Table 1). The reduction of adhesion in the presence of cancanavalin $\mathrm{A}$ is consistent with studies using chicken crop tissue whereas the inhibition by periodate is low compared to that reported by Fuller (1975). This may be due to the lower activity of periodate at $\mathrm{pH} 7$, to the longer incubation time of $4 \mathrm{~h}$ compared to $0.5 \mathrm{~h}$ in this study, or to the possibility that the carbohydrate groups are not solely responsible for adhesion to rodent epithelium as suggested by other studies (Suegara et al., 1975; Conway \& Adams, 1989). 
The culture supernatant fraction of both L. fermentum strains 737 and 737A had adhesionpromoting activity, indicating that $L$. fermentum strain $737 \mathrm{~A}$ maintained the capacity to produce an adhesive component, although it failed to retain it on the bacterial cell when grown in broth. The presence of a surface may trigger the bacterial cell to retain the adhesin on its surface as demonstrated here by growth on the agar surface.

The heat-sensitive, non-diffusable adhesion-promoting component in the culture supernatant fraction was specific for L. fermentum strains 737 and 737A. This is consistent with other studies which demonstrate the host specificity of adhesion of Lactobacillus spp. to chicken and rodent gastric epithelia (Fuller, 1973; Suegara et al., 1975; Lin \& Savage, 1984). Because adhesion of bacteria to mouse stomach epithelium was enhanced proportionally to the amount of the adhesion-promoting material added, it may be that adhesion is mediated by multiple binding sites on the bacterial cell surface. The adhesion-promoting factor could bind to either bacterial or epithelial surfaces. However, washing epithelium containing bound adhesin caused a reduction in binding. This may occur because receptors are also removed by the washing step. The fact that adhesion-promoting material was demonstrable in the dialysis retentates of spent culture supernatant fractions of all media including MRS diffusate broth, but with the exception of BHI broth containing erythrosine, supports the earlier concept that the bacteria produce an adhesion-promoting factor and that erythrosine inhibits the expression of this factor (Conway \& Adams, 1989).

The characterization of the adhesion-promoting determinant was simplified because the culture supernatant fraction contained this factor. Other studies directed at identification of adhesins on lactobacilli have involved treating whole bacterial cells with the various agents (e.g. Fuller, 1975; Suegara et al., 1975). Because of the complexity of the bacterial cell surface, it is difficult to distinguish between an indirect or a direct effect of various treatments on the adhesive determinants, as discussed by Fuller (1975), who showed that pepsin treatment released material from the bacterial surface which had an affinity for concanavalin $A$. The results of treating whole cells of L. fermentum strain 737 or the dialysis retentate of spent culture supernatant fractions with the various compounds before the assay illustrate this problem. Although the reduction of adhesion by concanavalin A and periodate treatments (Table 1) implies that carbohydrate groups play an active role in binding, the adhesion-promoting factor had no affinity for the immobilized lectin and was not affected by periodate (Table 4). The bacterial cell surface therefore contained groups with an affinity for the lectin which has a specificity for glucose, mannose, fructose or arabinose moieties with the alpha anomeric configuration (Sharon \& Lis, 1972). However, it is possible that Lactobacillus attachment may not utilize the groups with which the lectin reacted, but rather that steric hindrance by the concanavalin A here and when used by Fuller (1975) may have inhibited adhesion. Although the periodate was not as active in reducing adhesion of bacteria as reported by others, no reduction in adhesion was noted when the dialysis retentates of spent culture supernatant fractions were similarly treated. This confirmed that the action of periodate on whole cells was not oxidizing the adhesion-promoting factor.

The fact that cells still adhered and that the adhesion-promoting factor could be detected in the culture supernatant fraction after growth in the presence of tunicamycin suggests that adhesion was not mediated by a carbohydrate moiety, because this compound inhibits the formation of glycoproteins in some and most probably a wide range of systems (Elbein, 1981). The complete inactivation of the adhesion-promoting factor by pronase, and its partial inactivation by trypsin demonstrated its proteinaceous nature. 2-Dimensional gel electrophoresis confirmed the presence in the dialysis retentate of spent culture supernatant fraction of proteins which passed through the concanavalin A-Sepharose column and which were not present when erythrosine was included in the growth medium. Some evidence has been presented by other workers that a protein moiety may be involved, as adhesion to chicken epithelium was reduced by trypsin and by pepsin (Fuller, 1975) while adhesion to pig tissue was reduced by protease (Barrow et al., 1980). Similarly, the work of Suegara et al. (1975) using rat tissue implicates proteins because the adhesive determinant was destroyed by heating and SDS treatment. From the hydrophobic nature of L. fermentum strain 737 (Conway \& Adams, 1989), it 


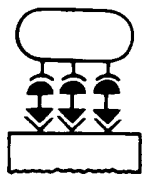

(a)

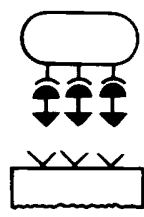

(c)

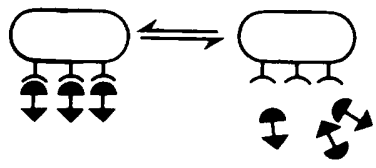

$(b l)$

(b2)

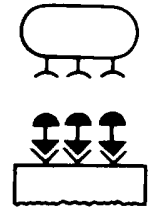

$(d)$

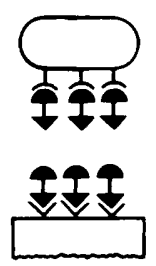

(e)

Fig. 3. Proposed model for various reactions observed for the proteinaceous adhesin of $L$. fermentum strain 737. (a) In vivo an adhesin molecule links bacterial cells to the epithelium. (b) In vitro the equilibrium between $(b l)$ and $(b 2)$ is influenced by culture conditions. When cells are cultured in broth and then washed, the equilibrium shifts towards (b2) thereby yielding bacterial cells with reduced adhesin on the surface. The extent of removal would be proportional to the washing procedure. (c) Cells from (b2) pretreated with adhesin prior to the in vitro adhesion assay. This addition facilitates adhesion as it also does when the tissue is pretreated as in $(d)$. (d) Epithelium pretreated with adhesin prior to incubation with cells from $(b 2)$. (e) Tissue cells and cells from (b2) pretreated with adhesin prior to the adhesion assay. This insertion of the adhesin on both surfaces binds all available sites such that when incubated together no receptors were available for the adhesins on the bacterial cell.

could be anticipated that the bacterium would have exposed protein moieties. Adhesion of $L$. fermentum strain 737 appears to involve a protein, $M_{\mathrm{r}} 12-13000$ which is not anionically charged and contains no active carbohydrate groups as well as no passive groups with an affinity for concanavalin A. As activity was also detected in a high- $M_{\mathrm{r}}$ fraction it is probable that the adhesin also aggregates with itself or other compounds.

A model is proposed (Fig. 3) to explain the location and action of the putative adhesive protein of $L$. fermentum strain 737 . An in vitro assay, as illustrated in Fig. $3(c-e)$, characterization of the adhesin was possible because the adhesin could be separated from the cells and subsequently used after various pretreatments directed towards destroying its adhesive activity. The Lactobacillus adhesin in the model is illustrated as having different terminal structures at each end. However, neither this model structure nor the location of the protein within the bacterial cell wall can be confirmed from the present data. At this cell-wall site, complexes may occur which could explain the suggestions of others on the complexity of binding (Suegara et al., 1975; Sherman \& Savage, 1986; Wadström et al., 1987).

The authors thank sincerely Åsa Jouper-Jaan for all the 2-dimensional electrophoresis work, K. C. Marshall for invaluable discussions and BioInvent International for financial support.

\section{REFERENCES}

Adams, R. F. \& Conway, P. L. (1981). The effect of erythrosine on the surface-associated bacteria of the rat stomach and caecum. Journal of Applied Bacteriology 51, 171-181.

Barrow, P. A., Brooker, B. E., Fuller, R. \& NEWPORT, M. J. (1980). The attachment of bacteria to the gastric epithelium of the pig and its importance in the microbiology of the intestine. Journal of Applied Bacteriology 48, 147-154.
Brooker, B. E. \& Fuller, R. (1975). Adhesion of lactobacilli to the chicken crop epithelium. Journal of Ultrastructure Research 52, 21-31.

Conway, P. L. \& ADams, R. F. (1989). Role of erythrosine in the inhibition of adhesion of Lactobacillus fermentum strain 737 to mouse stomach tissue. Journal of General Microbiology 135, 1167-1173.

Conway, P., Gorbach, S. L. \& Goldin, B. R. (1987). Survival of lactic acid bacteria in the human 
stomach and adhesion to intestinal cells. Journal of Dairy Science 70, 1-12.

Elbein, A. D. (1981). The tunicamycins - useful tools for studies on glycoproteins. TIBS 6, 219-221.

FUller, R. (1973). Ecological studies on the lactobacillus flora associated with the crop epithelium of the fowl. Journal of Applied Bacteriology 36, 131-139.

FULLER, R. (1975). Nature of the determinant responsible for adhesion of lactobacilli to chicken crop epithelial cells. Journal of General Microbiology 87, $245-250$.

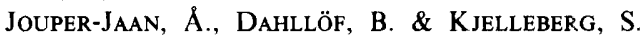
(1986). Changes in the protein composition of three marine isolates during starvation survival. Applied and Environmental Microbiology 52, 1419-1421.

KleEman, E. G. \& Klaenhammer, T. R. (1982). Adherence of Lactobacillus species to human fetal intestinal cells. Journal of Dairy Science 65, 20632069.

Kotarski, S. F. \& Savage, D. C. (1979). Models for study of the specificity by which indigenous lactobacilli adhere to murine gastric epithelia. Infection and Immunity 26, 966975 .

Lin, J. H.-C. \& SAVAGE, D. C. (1984). Host specificity of the colonization of murine gastric epithelium by lactobacilli. FEMS Microbiology Letters 24, 67-71.

MCCARTHY, D. M., Lin, J. H.-C., RinCKel, L. A. \& SAVAGE, D. C. (1988). Genetic transformation in Lactobacillus sp. strain $100-33$ of the capacity to colonize the non-secreting gastric epithelium in mice. Applied and Environmental Microbiology 54, 416-422.

SAvaGe, D. C. (1972). Association and physiological interaction of indigenous microorganisms and gastrointestinal epithelia. American Journal of Clinical Medicine 25, 1372-1379.
SavaGe, D. C. (1984). Overview of the association of microbes with epithelial surfaces. Microecology Therapy 14, 169-182.

SHARON, N. \& LIS, H. (1972). Lectins: cell-agglutinating and sugar specific proteins. Science 177, 949-959.

Sherman, L. A. \& SAVAGE, D. C. (1986). Lipoteichoic acids in Lactobacillus strains that colonize the mouse gastric epithelium. Applied and Environmental Microbiology 52, 302-304.

Suegara, N., Morotomi, M., Watanabe, T., KaWaI, Y. \& MUTAI, M. (1975). Behaviour of microflora in the rat stomach: adhesion of lactobacilli to the keratinized epithelial cells of the rat stomach in vitro. Infection and Immunity 12, 173-179.

Tannock, G. W., Szylit, O., Duval, Y. \& Raibuad, P. (1982). Colonization of tissue surfaces in the gastrointestinal tract of gnotobiotic animals by lactobacillus strains. Canadian Journal of Microbiology 28, 1196-1198.

Turakhia, M. H., Cooksey, K. E. \& Characklis, W. G. (1983). Influence of a calcium-specific chelant on biofilm removal. Applied and Environmental Microbiology 46, 1236-1238.

W AdSTRÖm, T., ANDERSSON, K., Sydow, M., AXelsSON, L., Lindgren, S. \& Gullmar, B. (1987). Surface properties of lactobacilli isolated from the small intestine of pigs. Journal of Applied Bacteriology 62, 513-520.

Whitaker, J. R. \& Garnum, P. E. (1980). An absolute method for protein determination based on difference in absorbance at 235 and $280 \mathrm{~nm}$. Analytical Biochemistry 109, 156-159. 